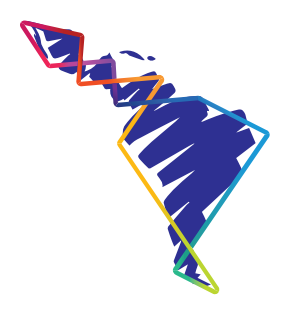

\title{
Protección del derecho a la propiedad privada de las personas naturales accionistas y socias de empresas en la jurisprudencia de la Corte Interamericana de Derechos Humanos
}

Protection of the right to private property of the natural person shareholder and partner of companies within the jurisprudence of the Inter-American Court of Human Rights

Proteção do direito à propriedade privada das pessoas naturais acionistas e sócios de empresas na jurisprudência da Corte Interamericana de Direitos Humanos

1 Doctora en Derecho de la Universidad Carlos III de Madrid. Investigadora de la organización I(dh)eas Litigio Estratégico de México en justicia transicional y derecho internacional de los derechos humanos, México. Correo electrónico: pythiasmayor@gmail.com. ORCID https://orcid.org/0000-0003-0040-7620 


\title{
Resumen
}

El artículo revisa la jurisprudencia de la Corte Interamericana de Derechos Humanos sobre la protección del derecho a la propiedad de las personas naturales accionistas de empresas. El objetivo es el de mostrar la forma en que esta Corte ha protegido el derecho, a pesar de la disposición del artículo 1.2 de la Convención Americana que excluye el reconocimiento de derechos de las personas jurídicas. Se sostiene en este artículo que la Corte Interamericana ha logrado proteger el derecho a la propiedad privada de las personas físicas accionistas por dos vías. La primera de ellas, a través de la distinción que ha hecho entre los derechos de las personas naturales socias o accionistas de una empresa y los derechos de la empresa misma como persona jurídica. Y la segunda, a través de la interpretación que ha hecho del agotamiento de los recursos internos, como requisito de admisibilidad previsto en el artículo 46.1.a) de la Convención Americana, cuando esos recursos solo pueden ser agotados por la persona jurídica y no por accionistas, al distinguir entre el análisis del agotamiento de los recursos y el análisis de la titularidad de los derechos de las personas jurídicas. De este modo, la Corte ha eliminado barreras de acceso a los órganos del Sistema Interamericano de Derechos Humanos y ha reafirmado el objeto y fin de la Convención como un instrumento que reconoce y protege los derechos humanos de todas las personas naturales.

Palabras clave: propiedad privada; derecho a la propiedad privada; protección de accionistas; propiedad en el sistema interamericano.

\begin{abstract}
The article reviews the jurisprudence of the Inter-American Court of Human Rights on the protection of the right to property of natural person shareholders of companies. The objective is to evidence the manner in which this Court has protected the right, despite the provision of Article 1.2 of the American Convention that excludes the recognition of rights of legal persons. The present work argues that the Inter-American Court has managed to protect the right to private property of natural person shareholders in two ways. First, through the distinction it has made between the rights of the natural person as a partner or shareholder of a company and the rights of the company itself as a legal person. Secondly, through the interpretation it has made regarding the exhaustion of domestic remedies, as an admissibility requirement set forth in Article 46.1.a) of the American Convention, when such remedies can only be exhausted by the legal person and not by shareholders, when distinguishing between the analysis of the exhaustion of resources and the analysis of the ownership of the rights of legal persons. In this manner, the Court has eliminated access barriers to the organs of the Inter-American Human Rights System and has reaffirmed the object and purpose of the Convention as an instrument that recognizes and protects the human rights of all natural persons.
\end{abstract}

Keywords: Private property; Right to private property; Shareholder protection; Property in the Inter-American System. 


\section{Resumo}

O artigo analisa a jurisprudência da Corte Interamericana de Direitos Humanos sobre a proteção do direito à propriedade das pessoas naturais acionistas das empresas. O objetivo é mostrar a maneira pela qual este Tribunal tem protegido o direito, apesar do disposto no artigo 1.2 da Convenção Americana que exclui o reconhecimento dos direitos das pessoas jurídicas. Argumenta-se neste artigo que a Corte Interamericana tem conseguido proteger o direito à propriedade privada dos acionistas pessoas físicas de duas maneiras. A primeira, pela distinção que fez entre os direitos das pessoas naturais sociais, ou sócios de uma empresa e os direitos da própria empresa como pessoa jurídica. E a segunda, através da interpretação que fez do esgotamento dos recursos internos, como requisito de admissibilidade previsto no artigo 46.1.a) da Convenção Americana, quando esses recursos só podem ser esgotados pela pessoa jurídica e não pelo acionistas, ao distinguir entre a análise do esgotamento de recursos e a análise da titularidade dos direitos das pessoas coletivas. Desta forma, a Corte eliminou barreiras de acesso aos órgãos do Sistema Interamericano de Direitos Humanos e reafirmou o objeto e a finalidade da Convenção como instrumento que reconhece e protege os direitos humanos de todas as pessoas naturais.

Palavras-chave: Propriedade privada; Direito à propriedade privada; Proteção aos acionistas; Propriedade no Sistema Interamericano.

\section{Introducción}

El reconocimiento del derecho a la propiedad como un derecho humano fundamental del cual serían titulares todos los seres humanos ha sido una cuestión disputada, no solo por quienes teorizan sobre el derecho a la propiedad (Álvarez, 2018; Sprankling, 2013), sino también en el propio seno de las Naciones Unidas. En 1993, la Comisión de Derechos Humanos presentó a la Asamblea General el informe del experto independiente Luis Valencia Rodríguez sobre El derecho de toda persona a la propiedad individual y colectiva, en cumplimiento de la Resolución 45/98 de 14 de diciembre de 1990 de la Asamblea General de las Naciones Unidas². En este informe, el experto consideró que: "El número de ratificaciones y adhesiones a los convenios universales que proclaman este derecho no permite afirmar que se trate de un derecho reconocido universalmente" (Valencia, 1993, p. 24). El informe se refiere, en particular, a las dificultades y diversidad de opiniones que se dieron durante la preparación del artículo que debería reconocer el derecho a la propiedad en los dos pactos internacionales de derechos civiles y políticos y de derechos económios sociales y culturales. Esas diferencias impidieron la redacción de un artículo que contara con la aceptación de todos los Estados y, en consecuencia,

2 La Resolución solicitaba a la Comisión de Derechos Humanos que "examinara la manera y la medida en que el respeto del derecho a la propiedad individual y colectiva contribuía a desarrollar la libertad y la iniciativa de la persona, como medio de fomentar, fortalecer y realzar el ejercicio de otros derechos humanos y libertades fundamentales". 
como Valencia (1993) señala, "los Pactos, tal como fueron aprobados el 16 de diciembre de 1966, no contienen disposición alguna sobre este derecho" (p.11)3.

La ausencia de reconocimiento del derecho en los dos grandes pactos internacionales de derechos humanos, sumado al hecho de que, para el momento en que Valencia presentó su informe, los tratados anteriores y posteriores a estos pactos que reconocían el derecho, no contaban con la ratificación de la mayoría de los Estados, permitía sostener que el derecho a la propiedad no tenía la calidad de un derecho humano reconocido universalmente en el derecho internacional y que su reconocimiento dependía de los derechos internos de los Estados. No obstante, como Sprankling (2013) ha señalado, después del informe de Valencia, el nivel de ratificación de los tratados en los que el derecho a la propiedad es reconocido se ha acelerado, al punto que se puede sostener que "el derecho global a la propiedad existe como una cuestión de derecho convencional" (Sprankling, 2013, p. 8). De hecho, el número actual de ratificaciones de varios de esos tratados es más elevado que el de las ratificaciones del Pacto Internacional de Derechos Civiles y Políticos (PIDCP) y del Pacto Internacional de Derechos Económicos, Sociales y Culturales (PIDESC) ${ }^{4}$.

Los tratados de derechos humanos en los que el derecho a la propiedad ha sido reconocido son tanto del sistema universal de las Naciones Unidas como de los sistemas regionales de derechos humanos. Alvarez (2018), Cheneval (2006), Golay \& Cismas (2010), Howard-Hassmann (2013), López (2015) y Sprankling (2013) han resaltado, en este sentido, que en todos los sistemas regionales el derecho a la propiedad es reconocido en los principales tratados 5 . En el sistema interamericano de derechos humanos, tanto la Declaración Americana de los Derechos y Deberes del Hombre de 1948 como la Convención Americana sobre Derechos Humanos de 1969 (en adelante Convención Americana o Convención) reconocen este derecho. En relación con la Convención Americana, la Corte Interamericana de Derechos Humanos (en adelante, Corte Interamericana o Corte) ha desarrollado, además, una amplia y consistente jurisprudencia en la que ha definido el contenido

3 Sobre las razones de estas dificultades y diferencias de opiniones entre los Estados, se puede ver, además del informe de Valencia, a López (2015, pp. 532-538). De acuerdo con este autor, las diferencias estuvieron determinadas por los intereses distintos que tenían los países capitalistas y los países comunistas y también por la diferencia de intereses que existía entre los países en proceso de descolonización.

$4 \mathrm{Al}$ momento de escribir este artículo, la Convención Internacional sobre la Eliminación de todas las Formas de Discriminación Racial había sido ratificada por 181 Estados; la Convención sobre la eliminación de todas las formas de discriminación contra la mujer por 189 Estados; y la Convención sobre los derechos de las personas con discapacidad por 180 Estados. El PIDCP por 173 Estados y el PIDESC por 169 Estados.

5 El derecho está reconocido en el sistema europeo en el artículo 1 del Protocolo Adicional al Convenio para la protección de los derechos humanos y de las libertades fundamentales de 1952; y en el sistema africano, en el artículo 14 de la Carta Africana sobre derechos humanos y de los pueblos de 1981. Una lista completa de los tratados en los que el derecho está reconocido en el sistema universal se puede ver en Álvarez (2018). 
y el alcance del derecho, así como las condiciones desde las cuales los Estados pueden, de conformidad con la Convención, intervenir o restringir este derecho.

El interés de este artículo está, precisamente, en la jurisprudencia de la Corte Interamericana y, en específico, en la jurisprudencia relacionada con la protección del derecho a la propiedad privada de las personas físicas o personas naturales que son accionistas o socias de empresas. La importancia de esta jurisprudencia reside, en primer lugar, en la forma en que la Corte ha garantizado, en estos casos, la protección del derecho a la propiedad, a pesar de que, contrario a lo que se prevé en el sistema europeo de derechos humanos en el que se protege el derecho a la propiedad de las personas jurídicas y de las personas físicas, la Convención Americana sobre Derechos Humanos excluye expresamente, en virtud del artículo 1.2, el reconocimiento y protección de los derechos de las personas jurídicas.

Conviene recordar, al respecto, que el artículo 1 del Protocolo Adicional al Convenio para la protección de los derechos humanos y de las libertades fundamentales del sistema europeo de derechos humanos prevé que toda persona "física o moral tiene derecho al respeto de sus bienes" y que nadie, incluidas las personas morales, "podrá ser privado de su propiedad sino por causa de utilidad pública y en las condiciones previstas por la ley y los principios generales del Derecho Internacional". El artículo 1.2 de la Convención Americana establece, por su parte, que, para los efectos de la Convención, "persona es todo ser humano". La Corte Interamericana (2016) ha dicho, sobre esta disposición, que es claro que de la lectura literal del artículo 1.2 de la Convención se excluye a otros tipos de personas que no sean seres humanos de la protección brindada por dicho tratado. Lo anterior implica, según esta Corte, "que las personas jurídicas en el marco de la Convención Americana no son titulares de los derechos establecidos en ésta $\mathrm{y}$, por tanto, no pueden presentar peticiones o acceder directamente, en calidad de presuntas víctimas y haciendo valer derechos humanos como propios, ante el sistema interamericano" (2016, párr. 38).

La jurisprudencia de la Corte Interamericana, en relación con el derecho a la propiedad privada de los accionistas de una empresa, es también importante por la reafirmación que la Corte ha hecho del objeto y fin de la Convención Americana como un instrumento protector de los derechos humanos de todas las personas naturales.

En esta perspectiva, la pregunta que se busca responder es: ¿cómo la Corte Interamericana ha protegido, en el marco de la Convención Americana sobre Derechos Humanos, el derecho a la propiedad privada de las personas naturales accionistas o socias de una empresa o compañía? En este escrito se sostiene que la Corte Interamericana de Derechos Humanos ha protegido el derecho a la propiedad 
privada de las personas naturales o personas físicas accionistas o socias de empresas por dos vías ${ }^{6}$. La primera de ellas, a través de la distinción que ha hecho entre, de una parte, los derechos de las empresas como personas jurídicas y, de la otra, los derechos de las personas físicas socias o accionistas de esas empresas. Y la segunda vía, a través de la interpretación que ha hecho del agotamiento de los recursos internos, como requisito de admisibilidad para acceder a los órganos de protección del sistema interamericano, cuando esos recursos solo pueden ser agotados por la persona jurídica y no por los accionistas o socios de una empresa o compañía. La Corte ha distinguido, en este caso, entre el análisis del agotamiento de los recursos internos y el análisis de la titularidad de los derechos de las personas jurídicas.

El desarrollo de estos dos aspectos se hace, en este artículo, siguiendo fundamentalmente las sentencias de la Corte Interamericana en los casos en los que se ha pronunciado sobre el derecho a la propiedad privada de las personas accionistas o socias de empresas, así como la Opinión Consultiva OC-22/16. El primer aspecto de la tesis se aborda en el primer apartado del escrito y el segundo aspecto corresponde al segundo apartado. Al final, se presentan las conclusiones.

\section{El derecho a la propiedad privada de las personas naturales accionistas o socias de una empresa en la jurisprudencia de la Corte Interamericana de Derechos Humanos}

La Corte Interamericana es conocida por la protección que ha dado, en una consolidada y pacífica jurisprudencia, al derecho de las comunidades indígenas y de los pueblos tribales a sus tierras y territorios ancestrales (Álvarez, 2018; Antkowiak, 2013; CIDH, 2015); así como por el amplio desarrollo que ha hecho, en esa jurisprudencia, del concepto de propiedad colectiva (Sauca y Wences, 2016). Sin embargo, conviene recordar que esta Corte inició su jurisprudencia sobre el derecho a la propiedad en casos en los que se alegaba la violación del artículo 21 de la Convención Americana?, como consecuencia de la violación del derecho a la propiedad privada de personas individuales. La jurisprudencia de la Corte Interamericana sobre el derecho a la propiedad privada individual es, como Álvarez (2018) y López (2015) han hecho notar, tan amplia y elaborada como lo es su jurisprudencia sobre el derecho a la propiedad colectiva de los pueblos indígenas y tribales.

El primer caso en que la Corte Interamericana conoció de un alegato de violación del artículo 21 de la Convención Americana sobre Derechos Humanos fue el Caso

6 En este artículo se usarán las expresiones "persona física” y "persona natural" con un mismo sentido: ser humano distinto de una persona jurídica.

7 El artículo 21 reconoce el derecho a la propiedad en estos términos: "1. Toda persona tiene derecho al uso y goce de sus bienes. La ley puede subordinar tal uso y goce al interés social”. 
Cesti Hurtado Vs. Perú. En este caso, la Corte (1999) señaló que "no se comprobó que hubo una violación, per se, del derecho del señor Cesti Hurtado sobre su propiedad" (párr. 183), pero no hizo una interpretación del artículo y, por tanto, no hizo una interpretación del contenido del derecho. La Corte hizo la primera interpretación del artículo 21 de la Convención en el Caso Ivcher Bronstein Vs. Perú, en el que se alegaba precisamente la violación del derecho a la propiedad privada del señor Bronstein. La Corte (2001a) señaló, en este caso, de manera expresa, que el artículo 21 reconoce el derecho a la propiedad privada, y definió, por primera vez, el concepto de "bienes" contemplado en este artículo. Al respecto, la Corte Interamericana (2001a) dijo que los bienes "son aquellas cosas materiales apropiables, así como todo derecho que pueda formar parte del patrimonio de una persona" (párr. 122). Según la Corte, este concepto comprende "todos los muebles e inmuebles, los elementos corporales e incorporales y cualquier otro objeto inmaterial susceptible de valor" (párr. 122). En sentencias posteriores, la propia Corte Interamericana ha caracterizado este concepto como un "concepto amplio de propiedad” (Corte IDH, 2005, párr. 102; Corte IDH, 2008, párr. 55).

El Caso Ivcher Bronstein Vs. Perú, en el que la Corte Interamericana reconoció por primera vez y de manera amplia el derecho a la propiedad privada como un derecho humano protegido en el artículo 21 de la Convención Americana coincidió, además, con el primer caso en el que la Corte tuteló este derecho a una persona física titular de una parte de las acciones de una empresa, el señor Bronstein. Después de este caso, el Tribunal Interamericano se ha pronunciado expresamente sobre el derecho a la propiedad privada de los accionistas o socios de una empresa en otros cuatro casos.

El señor Ivcher Bronstein era accionista mayoritario de una empresa de telecomunicaciones en Perú y, por decisión judicial, se había suspendido, a través de una medida cautelar, el ejercicio de sus derechos como accionista mayoritario y presidente de la empresa ${ }^{8}$. Esta decisión había producido, entre otras consecuencias, la imposibilidad del señor Bronstein de participar en las reuniones y decisiones de la junta directiva de la empresa, de transferir sus acciones, de recibir dividendos derivados de estas y de ejercer otros derechos que pudieran corresponderle como accionista (Corte IDH, 2001a).

La Corte Interamericana debía determinar, en este caso, en primer lugar, si las acciones son un bien en los términos del artículo 21 de la Convención Americana sobre Derechos Humanos y, en segundo lugar, debía establecer si tratándose de

8 El señor Bronstein había sido privado previamente de la nacionalidad peruana, un requisito para ser propietario de un medio de comunicación en Perú. 
la participación accionaria en una empresa esas acciones están protegidas por la Convención Americana de conformidad con el artículo 1.2 que establece que, para los efectos de esta Convención, persona es "todo ser humano" y que excluye, por tanto, los derechos de las personas jurídicas".

En relación con el primer aspecto, la Corte (2001a) consideró que la participación en el capital accionario "era susceptible de valoración y formaba parte del patrimonio de su titular desde el momento de su adquisición", esto es, "constituía un bien sobre el cual el señor Ivcher tenía derecho de uso y goce” (párr. 123). Por tanto, la participación accionaria (o las acciones) era un bien protegido por el artículo 21 de la Convención Americana. En relación con el segundo aspecto, la Corte Interamericana asumió la jurisprudencia de la Corte Internacional de Justicia en el Caso Barcelona Traction, Light and Power Company, Limited (Belgium v. Spain), en donde la Corte Internacional había distinguido entre los derechos de los accionistas y los derechos de la empresa. De acuerdo con la Corte Internacional de Justicia (1970), el concepto y la estructura de la empresa "se basan y determinan mediante una distinción firme entre la entidad separada de la compañía y la del accionista, cada una con un conjunto distinto de derechos" (párr. 41). De conformidad con esta distinción, los derechos del accionista pueden resultar directamente afectados en forma independiente de los derechos de la empresa como persona jurídica (ICJ, 1970, párr. 47). Siguiendo a la Corte Internacional de Justicia, la Corte Interamericana señaló que los derechos directos de los accionistas, diferentes de los derechos de la empresa, comprenden, entre otros, los derechos a asistir y votar en las juntas de la empresa, a recibir dividendos de sus acciones y a recibir parte de los activos de la empresa cuando esta se liquida. En el caso concreto, la Corte reconoció que el señor Bronstein era titular de esos derechos como accionista de la empresa de telecomunicaciones. Ahora, dada la forma en que se había proferido la decisión judicial que suspendió el ejercicio de sus derechos como accionista mayoritario, sin que mediaran razones de utilidad pública o de interés social ni se hubiera pagado al señor Bronstein una justa indemnización, tal como lo dispone el artículo 21 de la Convención Americana ${ }^{10}$, la Corte encontró que esa decisión era arbitraria y concluyó, en consecuencia, que "el Estado violó el derecho a la propiedad privada establecido en el artículo 21.1 y 21.2 de la Convención Americana, en perjuicio de Baruch Ivcher Bronstein" (Corte IDH, 2001a, párr. 131).

9 La Corte Interamericana ha definido a las personas jurídicas como "toda entidad que tenga existencia y responsabilidad propias, distintas a las de sus miembros o fundadores, y que sea calificada como persona jurídica según la ley del lugar de su constitución” (2016, párr. 28).

10 El artículo 21, numeral 2) de la Convención establece: "Ninguna persona puede ser privada de sus bienes, excepto mediante el pago de indemnización justa, por razones de utilidad pública o de interés social y en los casos y según las formas establecidas por la ley”. Un análisis amplio y detallado de la restricción legítima del derecho a la propiedad en la jurisprudencia de la Corte Interamericana, se puede ver en López (2015). 
En este primer caso, la Corte Interamericana reconoció el derecho a la propiedad privada como un derecho protegido en el artículo 21 de la Convención Americana sobre Derechos Humanos y reconoció, a la vez, el carácter de bienes que tienen las acciones o la participación accionaria en una empresa. Esas acciones están protegidas, como bienes, por el artículo 21 de la Convención Americana cuando su titular es, como el señor Ivcher Bronstein, una persona natural. La Corte reconoció, además, que la titularidad de las acciones da a los accionistas una serie de derechos directos, que son diferentes de los derechos de la empresa. Cuando se trata de personas físicas, esos derechos están igualmente protegidos por el artículo 21 de la Convención.

En un caso posterior, el Caso Cantos Vs. Argentina, aun cuando la Corte no se pronunció sobre la violación del derecho a la propiedad privada ${ }^{11}$, sí desarrolló la interpretación sobre la forma en que el artículo 21 de la Convención Americana reconoce este derecho a los socios de una empresa, de conformidad con el artículo 1.2. En este sentido, reiteró que el derecho a la propiedad privada de los socios de una empresa está reconocido en el artículo 21 de la Convención cuando los socios son personas físicas o personas naturales.

El señor José María Cantos era socio de varias empresas que fueron confiscadas por el Estado. Argentina alegaba, de acuerdo con el artículo 1.2 de la Convención Americana, que las personas jurídicas no están incluidas en la Convención. Según su argumento, si dos agricultores forman una sociedad para comprar una cosechadora y el gobierno la confisca, "ellos no podrán invocar la Convención Americana porque la cosechadora en cuestión sería propiedad de una sociedad" (Corte IDH, 2001b, párr. 25). La Corte señaló, sobre este argumento, varias cuestiones. Primero, que de acuerdo con la jurisprudencia del Caso Barcelona Traction, Light and Power Company, Limited (Belgium v. Spain) hay una diferencia entre los derechos de los accionistas de una empresa y los derechos de la empresa misma. Segundo, que los derechos y las obligaciones atribuidos a las personas morales "se resuelven en derechos y obligaciones de las personas físicas que las constituyen o que actúan en su nombre o representación". Y tercero, que la interpretación de Argentina conducía a "resultados irrazonables pues implica quitar la protección de la Convención a un conjunto importante de derechos humanos". Lo anterior, porque, según la Corte, el artículo 1.2 de la Convención Americana no restringe la posibilidad de que en determinados supuestos el individuo pueda acudir al sistema interamericano de protección de los derechos humanos "para hacer valer sus derechos fundamentales, aun cuando los mismos estén cubiertos por una figura o ficción jurídica creada por el mismo sistema del Derecho" (Corte IDH, 2001b, párr. 26-29).

11 La Corte (2002) se pronunció sobre la violación de los artículos 8 y 25 de la Convención Americana sobre Derechos Humanos. 
En el caso siguiente, Caso Chaparro Álvarez y Lapo Íñiguez Vs. Ecuador, la Corte Interamericana reafirmó su jurisprudencia sobre la distinción entre los derechos de los accionistas de una empresa y los derechos de la empresa, y recordó que hay una serie de derechos directos de los accionistas que están protegidos por el artículo 21 de la Convención Americana cuando los accionistas son personas naturales (Corte IDH, 2007).

En este caso, el señor Juan Carlos Chaparro Álvarez era un ciudadano chileno, propietario de una fábrica en Ecuador, y el señor Freddy Hernán Lapo Íñiguez, ciudadano ecuatoriano, era el gerente de la fábrica. Una jueza había ordenado como medida cautelar en un proceso penal la inmovilización de las acciones y de las cuentas corrientes y de ahorros que pudieran pertenecer a ambos, y había también prohibido enajenar los bienes que fueran de su propiedad y ordenado su incautación ${ }^{12}$. La Corte Interamericana constató, entre otros hechos, que el señor Chaparro Álvarez tenía una participación en las acciones de la empresa que alcanzaba el 50 \% del capital. Según la Corte (2007), esta participación en el capital accionario era "susceptible de valoración y formaba parte del patrimonio de su titular desde el momento de su adquisición", y, como tal, "constituía un bien sobre el cual el señor Chaparro tenía derecho de uso y goce" (párr. 182). Al analizar los hechos, la Corte encontró, además, varias violaciones al derecho a la propiedad privada del señor Chaparro Álvarez. Entre esas violaciones, la Corte señaló violaciones que lo afectaban directamente en su calidad de accionista. En concreto, la Corte señaló como violaciones del derecho a la propiedad privada del señor Chaparro Álvarez, en su calidad de accionista, la pérdida de valor y productividad de la fábrica, ocasionada por la no devolución de todos los bienes de la empresa una vez se levantó la medida cautelar. La Corte consideró que "la no devolución de bienes a la empresa incide en el valor y productividad de ésta, lo que a su vez perjudica a quienes son sus accionistas". Este perjuicio, según la Corte, "debe ser entendido como una intromisión arbitraria en el "goce" del bien, es decir, en el marco del artículo 21.1 de la Convención” (Corte IDH, 2007, párr. 209). Asimismo, la Corte Interamericana señaló como una violación del derecho a la propiedad privada, la imposibilidad del señor Chaparro Álvarez de continuar percibiendo las utilidades que recibía por el funcionamiento de la empresa, debido a la mala administración de la fábrica y deterioro de esta misma durante el tiempo que había estado incauta por el Estado. La Corte (2007) lo dijo en estos términos:

La Corte considera que el Estado es responsable por estos daños, toda vez que los bienes estuvieron bajo su custodia. Consecuentemente, declara que violó el derecho a la propiedad

12 Los señores Juan Carlos Chaparro Álvarez y Freddy Hernán Lapo Íñiguez habían sido detenidos arbitrariamente y acusados en un proceso sin las debidas garantías judiciales de delitos relacionados con el tráfico internacional de narcóticos, delitos de los que fueron absueltos. 
privada establecido en el artículo 21.1 de la Convención Americana, en relación con el artículo 1.1 de la misma, en perjuicio del señor Chaparro, puesto que, como consecuencia de la mala administración de la fábrica y los deterioros de la misma, el señor Chaparro fue privado arbitrariamente de la posibilidad de continuar percibiendo las utilidades que recibía con ocasión del funcionamiento de la empresa. (párr. 214)

La Corte Interamericana volvió a pronunciarse sobre el derecho a la propiedad privada de los accionistas de una empresa en el Caso Perozo y otros Vs. Venezuela, en donde reiteró su jurisprudencia sobre la diferencia de "los derechos de los accionistas de una empresa de los de la empresa misma" (2009, párr. 400). Esta diferenciación le permitió concluir, en este caso, que aun cuando estaba establecido que los señores Federico Ravell y Guillermo Zuloaga eran accionistas de la empresa propietaria de la emisora de televisión Globovisión (en torno a la cual giraban los hechos del caso), y, en esa medida, eran accionistas al menos de forma parcial de Globovisión, no se había probado que los daños ocasionados a la sede o a bienes de Globovisión, como empresa o persona jurídica, "se hayan traducido en una afectación de los derechos de los señores Ravell y Zuloaga, en tanto accionistas de la empresa" (Corte IDH, 2009, párr. 402). Por tanto, no se podía establecer que hubiera habido una violación del derecho a la propiedad privada de las personas naturales accionistas.

El otro caso en el que la Corte Interamericana se pronunció sobre la violación del derecho a la propiedad privada de los accionistas es el Caso Granier y otros (Radio Caracas Televisión) Vs. Venezuela. En esta ocasión, la Corte, si bien expresó de manera clara que "no es competente para analizar las presuntas violaciones a la Convención que se hayan ocurrido en contra de personas jurídicas" (2015, párr. 348), también reiteró lo que había señalado en el Caso Cantos Vs. Argentina, al decir que la Convención Americana no restringe la posibilidad de que "bajo determinados supuestos un individuo pueda acudir al Sistema Interamericano para hacer valer sus derechos, aun cuando los mismos estén cubiertos por una ficción jurídica creada por el mismo sistema jurídico" (2015, párr. 337). Y volvió a señalar, al respecto, que hay una diferencia entre los derechos directos de los accionistas de una empresa y los derechos de la misma empresa como persona jurídica. Entre los derechos directos de los accionistas están, como se había establecido en el Caso Ivcher Bronstein Vs. Perú, el derecho a "recibir los dividendos acordados, asistir y votar en las juntas generales y recibir parte de los activos de la compañía en el momento de su liquidación, entre otros" (Corte IDH, 2015, párr. 338). Atendiendo la distinción entre derechos de la empresa y derechos de los accionistas, la Corte señaló, en forma muy precisa, que el criterio para determinar si ha existido una vulneración al derecho de propiedad de los socios o accionistas de una empresa es que se encuentre probada claramente la afectación que ha recaído sobre sus 
derechos, distinta a las afectaciones generadas sobre el patrimonio de la empresa. En las palabras de la Corte (2015), "para determinar que ha existido una vulneración al derecho de propiedad de los socios es necesario que se encuentre probada claramente la afectación que sobre sus derechos ha recaído" (párr. 338). Al aplicar este criterio, la Corte concluyó, de manera similar a como lo hizo en el Caso Perozo y otros Vs. Venezuela, que no se había probado claramente que las medidas cautelares adoptadas sobre la empresa RCTV hubieran afectado el valor de la participación accionaria de los socios de la empresa y, por tanto, no se había demostrado una violación del derecho a la propiedad privada de los accionistas (2015).

La jurisprudencia de la Corte Interamericana, en estos casos, desde el Caso Ivcher Bronstein Vs. Perú, ha sido reiterativa y consistente en definir varias cuestiones que le han permitido proteger, en el marco del artículo 1.2 de la Convención Americana sobre Derechos Humanos, el derecho a la propiedad privada de las personas naturales que son accionistas o socias de una empresa. La Corte Interamericana ha establecido, en primer lugar, que las acciones o la participación de los socios en una empresa son bienes, en los términos del artículo 21 de la Convención Americana, en la medida en que entran a formar parte de su patrimonio. Esta Corte ha considerado, igualmente, que aun cuando la Convención Americana excluye el reconocimiento de los derechos de las personas jurídicas, no restringe la posibilidad de que, bajo determinados supuestos, las personas naturales que ejerzan sus derechos a través de ellas puedan acudir al sistema interamericano para hacer valer sus derechos fundamentales, aun cuando los mismos estén cubiertos por una figura o ficción jurídica creada por el mismo sistema jurídico. Estrechamente relacionado con esta cuestión, en los casos de accionistas o socios de empresa, el Tribunal Interamericano ha señalado expresamente que los derechos de los accionistas o socios son diferentes de los derechos de la empresa. En esta medida, si los accionistas o socios son personas naturales, las acciones o la participación en la empresa de la que son titulares constituye un bien que estaría protegido por el artículo 21 de la Convención Americana, sin que esta protección contradiga la exclusión de los derechos de las personas jurídicas prevista en el artículo 1.2 de esta Convención. Esa protección se extiende a los derechos directos que los accionistas tienen en razón de ser titulares de acciones o de una participación en la sociedad, entre ellos, el derecho a participar en las reuniones y decisiones de la junta directiva de la empresa, el derecho a transferir sus acciones y el derecho a recibir dividendos o utilidades derivados de estas. La protección del artículo 21 se concreta, de acuerdo con el criterio definido por la Corte, estableciendo con claridad si, en un caso específico, el derecho afectado ha sido el de la persona natural accionista y no el de la persona jurídica. 


\section{Agotamiento de los recursos internos por personas accionistas o socias de una empresa en la jurisprudencia de la Corte Interamericana de Derechos Humanos}

La regla del agotamiento de los recursos internos, como paso previo antes de acceder a mecanismos internacionales de protección frente a un Estado, es una regla del derecho consuetudinario y forma parte también de los principios generalmente reconocidos en el derecho internacional (Cabrera, 2016; Santalla, 2010). En el sistema interamericano de derechos humanos, el agotamiento de los recursos internos es un requisito que las personas o grupos de personas que buscan acceder a los órganos de protección del sistema deben cumplir necesariamente, salvo las situaciones previstas como excepciones a la regla del agotamiento. El artículo 46.1.a) de la Convención Americana sobre Derechos Humanos establece, al respecto, que para que una petición o comunicación presentada conforme al artículo 44 de la Convención ${ }^{13}$ sea admitida por la Comisión Interamericana de Derechos Humanos se requerirá "que se hayan interpuesto y agotado los recursos de jurisdicción interna, conforme a los principios del Derecho Internacional generalmente reconocidos". Es decir, como Faúndez (2007) explica:

antes de que el individuo pueda intentar que se establezca la responsabilidad internacional del Estado por la violación de alguno de los derechos consagrados en la Convención, y antes de que pueda recurrir a los órganos de la Convención, buscando una reparación por tales actos, debe, primero, recurrir a las instancias nacionales. (p. 9)

La Corte Interamericana (2016) ha dicho, en ese sentido, que la regla del agotamiento de los recursos internos "es una manifestación del principio de la colaboración o complementariedad del derecho internacional público" (párr. 122). Es una regla que está concebida en el derecho internacional en interés del Estado y tiene por finalidad "dispensarlo de responder ante un órgano internacional por actos que se le imputen, antes de haber tenido la ocasión de remediarlos con sus propios medios" (Corte IDH, 2015, párr. 29).

Según Faúndez (2007), la regla del agotamiento de los recursos internos se ha convertido en muchos casos "en una barrera insalvable para poder acceder a los órganos de protección previstos en la Convención Americana sobre Derechos Humanos" (p. 11). En el caso de las personas naturales o personas físicas que son accionistas o socias de una empresa, la dificultad para cumplir con la regla del

13 El artículo 44 de la Convención Americana sobre Derechos Humanos establece que: "Cualquier persona o grupo de personas, o entidad no gubernamental legalmente reconocida en uno o más Estados miembros de la Organización, puede presentar a la Comisión peticiones que contengan denuncias o quejas de violación de esta Convención por un Estado parte”. 
agotamiento de los recursos internos se presenta cuando, por normas del derecho interno del Estado, las personas naturales no están autorizadas legalmente para agotar directamente los recursos internos en caso de violación de derechos, porque ese agotamiento corresponde hacerlo al representante legal de la empresa, o cuando no pueden hacerlo, dada, por ejemplo, la composición accionaria compleja de la empresa; esto es, cuando los accionistas directos de la persona jurídica sobre la que se materializan las violaciones de derechos son otras personas jurídicas de las que, a su vez, son accionistas las personas naturales ${ }^{14}$.

La pregunta aquí es si el agotamiento de los recursos internos que la persona jurídica hace en esos casos es compatible con lo establecido en el artículo 46.1.a) de la Convención Americana sobre Derechos Humanos, es decir, si ese agotamiento permitiría a las personas naturales sostener ante la Comisión Interamericana y ante la Corte que han cumplido con ese requisito de admisibilidad.

La Corte Interamericana se pronunció expresamente sobre este punto en la Opinión Consultiva OC-22/16 de 26 de febrero de 2016, emitida en respuesta a la solicitud de la República de Panamá de 28 de abril de 2014.

Es importante recordar que el propósito de la función consultiva que la Corte tiene, de acuerdo con el artículo 64 de la Convención Americana, es el de "obtener una interpretación judicial sobre una o varias disposiciones de la Convención o de otros tratados concernientes a la protección de los derechos humanos en los Estados americanos" (Corte IDH, 2016, párr. 26) ${ }^{15}$. La función consultiva de la Corte, como función judicial ejercida con base en la Convención, está destinada a "ayudar a los Estados y órganos a cumplir y a aplicar tratados en materia de derechos humanos, sin someterlos al formalismo y al sistema de sanciones que caracteriza el proceso contencioso" (Corte IDH, 1983, párr. 43). En este sentido, la propia Corte (1997) ha señalado que la opinión consultiva que ella emite tiene "efectos jurídicos innegables" (párr. 26) ${ }^{16}$.

La precisión hecha por la Corte sobre los efectos jurídicos de sus opiniones consultivas es importante porque, en relación con la Opinión Consultiva OC-22/16 de 26 de febrero de 2016, la Corte señaló que esta Opinión Consultiva determina "la interpretación y el alcance del artículo 1.2 de la Convención Americana en el marco de las preguntas planteadas por el Estado solicitante" (2016, párr. 32).

14 La Corte Interamericana se ocupó de esta forma compleja de organización accionaria de las empresas en el Caso Granier y otros (Radio Caracas Televisión) Vs. Venezuela ya mencionado.

15 El artículo 64.1 de la Convención Americana sobre Derechos Humanos prevé que los Estados miembros de la OEA "podrán consultar a la Corte acerca de la interpretación de esta Convención o de otros tratados concernientes a la protección de los derechos humanos en los Estados americanos". Asimismo, podrán consultarla, en lo que les compete, los órganos enumerados en el capítulo X de la Carta de la OEA.

16 Sobre las opiniones consultivas de la Corte Interamericana se puede ver a Salvioli (2004). 
Entre las preguntas formuladas por Panamá a la Corte en la solicitud de opinión consultiva estaban las siguientes:

¿Pueden las personas jurídicas acudir a los procedimientos de la jurisdicción interna y agotar los recursos de la jurisdicción interna en defensa de los derechos de las personas físicas titulares de esas personas jurídicas?

¿Puede una empresa o sociedad privada, cooperativa, sociedad civil o sociedad comercial, un sindicato (persona jurídica), un medio de comunicación (persona jurídica), una organización indígena (persona jurídica), en defensa de sus derechos y/o de sus miembros, agotar los recursos de la jurisdicción interna y acudir a la Comisión Interamericana de Derechos Humanos en nombre de sus miembros (personas físicas asociadas o dueñas de la empresa o sociedad), o debe hacerlo cada miembro o socio en su condición de persona física? (Corte IDH, 2016, párr. 3)

Es decir, Panamá planteó explícitamente a la Corte Interamericana la cuestión de si el agotamiento de recursos internos realizado por las personas jurídicas y no por los accionistas o socios, como personas físicas o personas naturales, les permitía a estos cumplir con el requisito de admisibilidad de agotar previamente los recursos internos para acudir a la Comisión Interamericana y a la Corte buscando la protección de sus derechos. Las respuestas de la Corte a las preguntas de Panamá deben entenderse, de conformidad con su propia jurisprudencia sobre los efectos de las opiniones consultivas, como respuestas con efectos jurídicos, que indican, a los Estados del sistema interamericano, la forma en que deben cumplir y aplicar el artículo 1.2 de la Convención Americana en los casos en los que las personas naturales solo puedan agotar los recursos internos a través de una persona jurídica.

Antes de abordar este punto, la Corte Interamericana reafirmó, como lo había expresado en el Caso Cantos Vs. Argentina y en el Caso Granier y otros (Radio Caracas Televisión) Vs. Venezuela, que las personas jurídicas en el marco de la Convención Americana no son titulares de los derechos establecidos en esta y, por tanto, "no pueden presentar peticiones o acceder directamente, en calidad de presuntas víctimas y haciendo valer derechos humanos como propios, ante el sistema interamericano" (Corte IDH, 2016, párr. 38) ${ }^{17}$. No obstante, la Corte señaló también que el ejercicio de ciertos derechos de las personas naturales, como el derecho a la propiedad y el derecho a la libertad de expresión, se realiza "a través de personas jurídicas" (2016, párr. 112).

17 Es importante señalar que en esta Opinión Consultiva la Corte Interamericana estableció que, de acuerdo con el derecho internacional, la situación de las comunidades y pueblos indígenas y tribales y la de las organizaciones sindicales, por sus particularidades, es diferente. Para un análisis de estos dos aspectos de la Opinión Consultiva, se puede ver a Barbaresco (2017). 
Ahora, para responder específicamente a la cuestión del agotamiento de los recursos internos por las personas jurídicas en defensa de personas físicas, la Corte Interamericana constató, en primer lugar, "que el artículo 46.1.a) no hace ninguna distinción entre personas naturales o personas jurídicas, puesto que se concentra exclusivamente en el agotamiento de los recursos" (2016, párr. 133). La Corte señaló, además, al respecto:

este Tribunal ha sostenido que según la regla del efecto útil, la norma está encaminada a producir un efecto y no puede interpretarse en el sentido de que no produzca ninguno o su resultado sea manifiestamente absurdo o irrazonable. Por ello, la Corte no puede interpretar el artículo 46.1.a) de modo que limite el acceso al sistema interamericano por parte de posibles víctimas y se genere una desprotección de las mismas. En este sentido, la Corte considera que resulta desproporcionado obligar a una presunta víctima a interponer recursos inexistentes, cuando se comprueba que el recurso idóneo y efectivo era el agotado por parte de la persona jurídica. (2016, párr. 133)

La Corte señaló, asimismo, que el agotamiento de los recursos internos "supone un análisis independiente del referente a la titularidad de derechos por parte de personas jurídicas" (2016, párr. 135). En este sentido, el estudio del cumplimiento del requisito del agotamiento de los recursos internos, como un requisito de admisibilidad, debe centrarse solo en que se hayan presentado los recursos idóneos y efectivos en el ámbito interno, "independientemente de si el recurso fue interpuesto por una persona natural o una jurídica" (2016, párr. 139).

Esta interpretación de la Corte es de suma importancia, si se tiene en cuenta que en el sistema interamericano existía el precedente de la decisión de la Comisión Interamericana de Derechos Humanos en el Caso Bendeck-Cohdinsa v. Honduras. En este caso, la Comisión Interamericana había concluido que, si bien el señor Bendeck era accionista mayoritario de una empresa (la Compañía Hondureña de Inversiones, S.A. de C.V. -COHDINSA), ella tenía competencia ratione personae para conocer su petición "por cuanto ha sido presentada por "una persona", el señor Bendeck y por cuanto "persona", según el artículo 1(2) de la Convención, es "todo ser humano"” (CIDH, 1999, párr. 4). Sin embargo, la Comisión consideró que la petición era inadmisible, porque aun cuando el señor Bendeck era la presunta víctima de los hechos, "los recursos jurisdiccionales internos no fueron agotados por él en nombre propio o en su carácter de accionista, sino por COHDINSA, un ente con personalidad jurídica" (CIDH, 1999, párr. 4). Es decir, la Comisión negó, en este caso, la admisibilidad de la petición porque el señor Bendeck, como persona natural, no había cumplido con la regla del agotamiento de los recursos internos.

Con la interpretación de la Corte, no hay ya duda de que, para efectos del análisis de admisibilidad de una petición en el sistema interamericano, lo que interesa 
establecer, en los casos en los que la persona natural es accionista o socia de una empresa, es si los recursos internos fueron agotados o bien por la persona natural o bien por la persona jurídica.

La Corte concluyó, finalmente, en coherencia con la interpretación anterior, que la interposición de recursos internos por parte de personas jurídicas "no implica per se que no se hayan agotado los recursos internos por parte de las personas físicas titulares de los derechos convencionales, por lo que el cumplimiento de este requisito deberá ser analizado en cada caso" (2016, párr. 139).

La Opinión Consultiva OC-22/16 de 26 de febrero de 2016 es, como Barbaresco (2017) ha señalado, de suma importancia. En relación con las personas físicas, accionistas o socias de una empresa, su importancia reside en la claridad con la que la Corte estableció la vía de acceso a la protección de los órganos del sistema interamericano en los casos en los que las personas naturales accionistas o socias de una empresa no pueden agotar, por ellas mismas, los recursos internos, porque dependen del agotamiento de estos recursos por parte de la persona jurídica.

Como Faúndez (2007) ha expresado, una de las cuestiones centrales que la Comisión Interamericana y la Corte deben decidir es cómo armonizar, frente a la falta de protección por los órganos de jurisdicción interna de los derechos de una persona, la exigencia del agotamiento de los recursos internos con el propósito último y el objetivo primordial del sistema interamericano de protección de los derechos humanos. Faúndez (2007) ha dicho, al respecto:

La respuesta que se dé a las preguntas anteriores tiene especial relevancia en el ámbito de los derechos humanos. De tales respuestas, y de la interpretación que de esta regla se haga en el marco de la Convención Americana sobre Derechos Humanos, dependerá la eficacia del sistema de protección de los derechos humanos diseñado por esta última, al igual que la utilidad de las peticiones o denuncias que los individuos puedan someter a la Comisión Interamericana de Derechos Humanos. (p. 12)

En la Opinión Consultiva OC-22/16 de 26 de febrero de 2016, la Corte Interamericana armonizó con mucha precisión el objetivo último del sistema interamericano, como sistema de protección de los derechos humanos de las personas naturales, con la regla del agotamiento de los recursos internos, al establecer que el análisis del agotamiento de estos recursos, como requisito de admisibilidad, debe centrarse solo en establecer que se han agotado, con independencia de la persona natural o jurídica que haya interpuesto el respectivo recurso. Con esta interpretación, la Corte eliminó la barrera que las personas naturales accionistas o socias de una empresa enfrentan cuando, por disposiciones del derecho del país, no pueden 
agotar directamente los recursos internos en defensa de sus derechos y, por tanto, no pueden agotarlos como requisito previo necesario para poder acudir al sistema interamericano en busca de la protección de estos mismos.

En relación con el derecho a la propiedad privada de las personas naturales accionistas o socias de una empresa o compañía, la eliminación de esa barrera se suma a la protección que la Corte ha venido otorgando a este derecho desde el Caso Ivcher Bronstein Vs. Perú, en la medida en que el agotamiento de los procedimientos domésticos por parte de la persona jurídica de la que las personas físicas o naturales son accionistas o socias no será ya un obstáculo jurídico para buscar la protección de su derecho ante la Comisión Interamericana y la Corte.

\section{Conclusiones}

La jurisprudencia de la Corte Interamericana sobre el derecho a la propiedad privada individual es tan amplia y elaborada como lo es su jurisprudencia sobre el derecho a la propiedad colectiva de los pueblos indígenas y tribales. La Corte hizo la primera interpretación del artículo 21 de la Convención Americana sobre Derechos Humanos en un caso en el que se alegaba, precisamente, la violación del derecho a la propiedad privada de un individuo, el Caso Ivcher Bronstein Vs. Perú. Este caso coincidió con el primero en el cual la Corte Interamericana tuteló el derecho a la propiedad privada de una persona física titular de una parte de las acciones de una empresa.

La Corte Interamericana ha protegido el derecho a la propiedad privada de las personas físicas accionistas o socias de empresas al reconocer, desde el Caso Ivcher Bronstein Vs. Perú, que las acciones son bienes, en los términos del artículo 21 de la Convención, y que, como tales, están protegidas por ese artículo cuando sus titulares son personas naturales. La Corte estableció este reconocimiento después de concluir, como lo había hecho antes la Corte Internacional de Justicia en el Caso Barcelona Traction, Light and Power Company, Limited (Belgium v. Spain), que los derechos de las empresas son distintos de los derechos de sus accionistas o socios. $\mathrm{Al}$ asumir esta distinción, la Corte Interamericana pudo diferenciar los derechos de las personas naturales accionistas o socias de una empresa de los derechos de la empresa misma. De este modo, la Corte Interamericana ha podido proteger el derecho a la propiedad privada de los accionistas, así como los derechos que derivan de la titularidad de las acciones, cuando estos accionistas son personas naturales, sin contravenir la exclusión que el artículo 1.2 de la Convención hace de los derechos de las personas jurídicas.

Asimismo, la Corte Interamericana ha protegido el derecho a la propiedad privada de las personas físicas accionistas o socias de empresas al establecer, 
respecto del agotamiento de los recursos internos, en primer lugar, que el artículo 46.1.a) de la Convención Americana no hace ninguna distinción entre personas naturales o personas jurídicas, pues se concentra exclusivamente en el agotamiento de los recursos, y, en segundo lugar, que el análisis del agotamiento de los recursos internos es independiente del análisis de la titularidad de derechos por parte de las personas jurídicas. El estudio del cumplimiento del requisito del agotamiento de los recursos internos, como un requisito de admisibilidad, debe centrarse, por tanto, solo en que se hayan agotado los recursos idóneos y efectivos en el ámbito interno, independientemente de si el recurso fue interpuesto por una persona natural o por una persona jurídica. Con esta interpretación, la Corte eliminó la barrera que las personas naturales accionistas o socias de una empresa enfrentan cuando, por disposiciones del derecho del país, no pueden agotar directamente los recursos internos como requisito previo necesario para poder acudir a los órganos del sistema interamericano de derechos humanos en búsqueda de la protección de sus derechos.

\section{Referencias}

Alvarez, J. (2018). The Human Right of Property. University of Miami Law Review, 72(3), 580705. https://repository.law.miami.edu/cgi/viewcontent.cgi?article $=4533 \&$ context $=$ umlr

Antkowiak, T. (2013). Rights, Resources and Rhetoric: Indigenous Peoples and the Inter-American Court. U. PA. J. INT'L L, 35(1), 113-187. https://digitalcommons.law.seattleu.edu/ cgi/viewcontent.cgi?article $=1432 \&$ context $=$ faculty

Barbaresco, M. (2017). ¿Son las personas jurídicas titulares de derechos humanos? Revista no hay derecho. http://www.iidhamerica.org/detalles-nhd.php?id=29

Cabrera, A. (2016). The Exhaustion of Domestic Remedies and the Notion of an Early Stage in the Case of Brewer Carías. Is the Inter-American Human Rights System at Risk? Mexican Law Review, 8(2), 151-168. https://doi.org/10.1016/j.mexlaw.2016.07.006

Cheneval, F. (2006). Property Rights as Human Rights. En H. De Soto y F. Cheneval (Ed), Realizing Property Rights (pp.11-17). Ruffer \& Rub Pub.

CIDH. (1999). Informe N.ำ 106/99. Bendeck-Cohdinsa v. Honduras, 27 de septiembre de 1999. https://www.cidh.oas.org/annualrep/99span/Inadmisible/Honduras.Bendeck.htm

CIDH. (2015). Pueblos indígenas, comunidades afrodescendientes y recursos naturales: Protección de derechos humanos en el contexto de actividades de extracción, explotación y desarrollo. OEA/ Ser.L/V/II. Doc. 47/15 31. http://www.oas.org/es/cidh/informes/pdfs/IndustriasExtractivas2016.pdf 
Corte IDH. (1983). Restricciones a la pena de muerte (arts. 4.2 y 4.4 Convención Americana sobre Derechos Humanos), Opinión consultiva OC-3/83 del 8 de setiembre de 1983. Serie A No. 3. http://www.corteidh.or.cr/docs/opiniones/seriea_03_esp.pdf

Corte IDH. (1997). Informes de la Comisión Interamericana de Derechos Humanos (Art. 51 Convención Americana sobre Derechos Humanos). Opinión Consultiva OC-15/97 de 14 de noviembre de 1997. Serie A No. 15. http://www.corteidh.or.cr/docs/opiniones/ seriea_15_esp.pdf

Corte IDH. (1999). Caso Cesti Hurtado Vs. Perú. Fondo. Sentencia de 29 de septiembre de 1999. Serie C No. 56. http://www.corteidh.or.cr/docs/casos/articulos/seriec_56_esp.pdf

Corte IDH. (2001a). Caso Ivcher Bronstein Vs. Perú. Fondo, Reparaciones y Costas. Sentencia de 6 de febrero de 2001. Serie C No. 74. http://www.corteidh.or.cr/docs/casos/articulos/ seriec_74_esp.pdf

Corte IDH. (2001b). Caso Cantos Vs. Argentina. Excepciones Preliminares. Sentencia de 7 de septiembre de 2001. Serie C No. 85. http://www.corteidh.or.cr/docs/casos/articulos/ Seriec_85_esp.pdf

Corte IDH. (2002). Caso Cantos Vs. Argentina. Fondo, Reparaciones y Costas. Sentencia de 28 de noviembre de 2002. Serie C No. 97. http://www.corteidh.or.cr/docs/casos/articulos/ seriec_97_esp.pdf

Corte IDH. (2005). Caso Palamara Iribarne Vs. Chile. Fondo, Reparaciones y Costas. Sentencia de 22 de noviembre de 2005. Serie C No. 135. http://www.corteidh.or.cr/docs/casos/ articulos/seriec_135_esp.pdf

Corte IDH. (2007). Caso Chaparro Álvarez y Lapo Íñiguez Vs. Ecuador. Excepciones Preliminares, Fondo, Reparaciones y Costas. Sentencia de 21 de noviembre de 2007. Serie C No. 170. http://www.corteidh.or.cr/docs/casos/articulos/seriec_170_esp.pdf

Corte IDH. (2008). Caso Salvador Chiriboga Vs. Ecuador. Excepción Preliminar y Fondo. Sentencia de 6 de mayo de 2008. Serie C No. 179. http://www.corteidh.or.cr/docs/casos/ articulos/seriec_179_esp.pdf

Corte IDH. (2009). Caso Perozo y otros Vs. Venezuela. Excepciones Preliminares, Fondo, Reparaciones y Costas. Sentencia de 28 de enero de 2009. Serie C No. 195. http://www. corteidh.or.cr/docs/casos/articulos/seriec_195_esp.pdf

Corte IDH. (2015). Caso Granier y otros (Radio Caracas Televisión) Vs. Venezuela. Excepciones Preliminares, Fondo, Reparaciones y Costas. Sentencia de 22 de junio de 2015. Serie CNo. 293. http://www.corteidh.or.cr/docs/casos/articulos/seriec_293_esp.pdf 
Corte IDH. (2016). Opinión Consultiva OC-22/16 de 26 de febrero de 2016. Titularidad de derechos de las personas jurídicas en el sistema interamericano de derechos humanos (interpretación y alcance del artículo 1.2, en relación con los artículos 1.1, 8, 11.2, 13, 16, 21, 24, 25, 29, 30, 44, 46 y 62.3 de la Convención Americana sobre Derechos Humanos, así como del artículo 8.1.a y b del Protocolo de San Salvador). http://www.corteidh.or.cr/ docs/opiniones/seriea_22_esp.pdf

Faúndez, H. (2007). El agotamiento de los recursos internos en el sistema interamericano de protección de los derechos humanos. UCV-IIDH.

Golay, Ch., \& Cismas, I. (2010). Legal Opinion: The Right to Property from a Human Rights Perspective. http://dx.doi.org/10.2139/ssrn.1635359

Howard-Hassmann, R. (2013). Reconsidering the Right to Own Property. Journal of Human Rights, 12(2), 180-197. https://doi.org/10.1080/14754835.2013.784667

ICJ. (1970). Case Concerning the Barcelona Traction, Light and Power Company, Limited. Judgment of 5 February 1970. https://www.icj-cij.org/files/case-related/50/050-19700205JUD-01-00-EN.pdf

López, S. (2015). La propiedad y su privación o restricción en la jurisprudencia de la Corte Interamericana. Revista Ius et Praxis, 21 (1), 531 - 576. http://dx.doi.org/10.4067/ S0718-00122015000100015

Salvioli, F. (2004). La competencia consultiva de la Corte Interamericana de Derechos Humanos: Marco legal y desarrollo jurisprudencial. En S. Fabris (Ed), Homenaje y Reconocimiento a Antônio Cançado Trindade T III (pp. 417 - 472). http://www.derechoshumanos.unlp. edu.ar/assets/files/documentos/la-competencia-consultiva-de-la-corte-interamericana-de-derechos-humanos-marco-legal-y-desarrollo--2.pdf

Santalla, E. (2010). Agotamiento de recursos internos y principio de complementariedad: ¿Dos caras de la misma moneda? En G. Elsner, K. Ambos y E. Malarino (Ed), Sistema interamericano de protección de los derechos humanos y derecho penal internacional (Vol. 2, pp. 517-542). Editorial Konrad-Adenauer Stiftung.

Sprankling, J. (2013). The Global Right to Property. Columbia Journal of Transnational Law, 52, 1-31. https://ssrn.com/abstract $=2245765$

Sauca, J. y Wences, I. (2016). Derechos colectivos (en la doctrina de la Corte Interamericana de Derechos Humanos). Eunomía. Revista en Cultura de la Legalidad, 9, 195-204. https://e-revistas.uc3m.es/index.php/EUNOM/article/view/2821/1517

Valencia, L. (1993). El derecho de toda persona a la propiedad individual y colectiva. E/CN.4/1994/19, 25 de noviembre de 1993. https://documents-dds-ny.un.org/doc/UNDOC/GEN/ G93/857/18/PDF/G9385718.pdf?OpenElement 
